\title{
Long-term Follow-up and Muscle Imaging Findings in Brachio-Cervical Inflammatory Myopathy
} Matteo Lucchini, MD, * Sara Bortolani, MD, * Mauro Monforte, MD, Manuela Papacci, BSc, Enzo Ricci, MD, PhD,
Massimiliano Mirabella, MD, PhD, and Giorgio Tasca, MD

Neurol Neuroimmunol Neuroinflamm 2021;8:e1016. doi:10.1212/NXI.0000000000001016
Correspondence

Dr. Lucchini

lucchinimatteo87@gmail.com

Prof. Mirabella

massimiliano.mirabella@unicatt.it

\section{Abstract}

\section{Objective}

To report on a cohort of patients diagnosed with brachio-cervical inflammatory myopathy (BCIM), with specific focus on muscle MRI and follow-up data.

\section{Methods}

Clinical, histopathologic, serologic, and pre- and post-treatment MRI findings of patients diagnosed with BCIM were retrospectively evaluated.

\section{Results}

Six patients, all females with a mean age at onset of 53 years (range 37-62 years), were identified. Mean diagnostic delay was 17 months, and mean follow-up was 35 months. Most common clinical features encompassed predominant involvement of neck and proximal upper limb muscles, followed by distal upper limb, facial, and bulbar muscle weakness with different severity. Lower limb involvement was rare, although present in severe cases. Muscle biopsies showed a heterogeneous degree of perivascular and endomysial inflammatory changes. Myositis-specific antibodies were absent in all patients, whereas all resulted positive for antinuclear antibodies; half of the patients had anti-acetylcholine receptor antibodies without evidence of muscle fatigability. MRI showed disproportionate involvement of upper girdle and neck muscles compared with lower limbs, with frequent hyperintensities on short-tau inversion recovery sequences. Partial clinical and radiologic improvement with steroid and immunosuppressant therapy was obtained in most patients, especially in proximal upper limb muscles, whereas neck weakness persisted.

\section{Conclusion}

BCIM is an inflammatory myopathy with a peculiar clinical and radiologic presentation and a relatively broad spectrum of severity. Long-term follow-up data suggest that appropriate and early treatment can prevent chronic muscle function impairment. MRI characterization can be helpful in reducing diagnostic and treatment delay with positive consequence on clinical outcome. 


\section{Glossary}

ANA = antinuclear antibody; $\mathbf{A c h R}=$ acetylcholine receptor; $\mathbf{B C I M}=$ brachio-cervical inflammatory myopathy; $\mathbf{C K}=$ creatine kinase; DM = dermatomyositis; FSHD = facioscapulohumeral muscular dystrophy; IIM = idiopathic inflammatory myopathy; IVIg = IV immunoglobulin; MAA = myositis-associated antibody; $\mathbf{M A C}=$ membrane attack complex; $\mathbf{M R C}=$ Medical Research Council; MSA = myositis-specific antibody; NCS = nerve conduction study; OPES = oro-pharyngo-esophageal scintigraphy; $\mathbf{P M}=$ polymyositis; STIR = short-tau inversion recovery; STIR+ = STIR hyperintensity; T1 $\mathbf{w}=$ T1 weighted.

Idiopathic inflammatory myopathies (IIMs) are a heterogeneous group of acquired, immune-mediated diseases, primarily involving skeletal muscle and classified on specific histopathologic, clinical, and serologic features. ${ }^{1-4}$ From a clinical perspective, IIMs are usually characterized by the symmetrical weakness of lower limb and, to a lesser extent, proximal upper limb muscles. Elevated muscle tissue enzymes such as creatine kinase (CK) and the presence of myositis-specific (MSAs) and myositisassociated antibodies (MAAs) are key laboratory findings. Traditionally, IIMs have been classified into 3 main subtypes: polymyositis (PM), dermatomyositis (DM), and sporadic inclusion body myositis. More recently, other subtypes have been identified by having homogeneous clinical, pathologic, and serologic findings, such as antisynthetase syndrome and immunemediated necrotizing myopathy. ${ }^{5,6}$ Beyond these forms, other rarer IIMs with peculiar features have been described, brachiocervical inflammatory myopathy (BCIM) being one of them. First reported in $2006,{ }^{7}$ BCIM is characterized by prominent neck and upper limb weakness with a relative sparing of lower limbs and is frequently associated with other autoimmune features, such as the presence of antinuclear (ANAs) or antiacetylcholine receptor (AchR) antibodies. For these reasons, possible differential diagnoses are myasthenia gravis, motor neuron disease, overlap inflammatory myopathies, or facioscapulohumeral muscular dystrophy (FSHD).

After the first description of this entity, only few other reports have been published, mostly highlighting the prevalence of the disease among the female patients and the response to immunosuppressive agents. ${ }^{8-11} \mathrm{MRI}$, that has been lately used in genetic and inflammatory myopathies for diagnostic purposes, sometimes providing specific patterns of involvement, and in follow-up, for the evaluation of disease progression and treatment response, has not been systematically investigated in BCIM. ${ }^{12,13}$

Here, we report clinical and instrumental findings of patients followed at the Fondazione Policlinico Universitario A. Gemelli IRCCS affected by BCIM focusing on radiologic, histopathologic, and serologic assessments at baseline and after long-term follow-up.

\section{Methods}

\section{Patients}

We reviewed all the medical records of patients with IIM available at our neuromuscular center from 2006 to 2019 and selected those with a diagnosis of BCIM. For all patients, the following clinical information was collected: age, sex, age at disease onset, disease duration, symptoms at disease onset, disease course, and comorbidities. Neurologic examination data were collected, and muscle strength was assessed and graded according to the Medical Research Council (MRC) score.

\section{Standard Protocol Approvals, Registrations, and Patient Consents}

This study was approved by the ethics committee of the Università Cattolica del Sacro Cuore (Rome, Italy; protocol 5098/14), and all patients gave written informed consent.

\section{Laboratory and Instrumental Examinations}

CK level and assays for MSA, MAA, ANA, ENA, anti-dsDNA, and anti-AchR antibodies were performed in all patients. The following MSAs and MAAs were tested using a commercial line blot test (Euroimmun AG, Lübeck, Germany): Mi-2 alfa, Mi-2 beta, TIF1g, MDA5, NXP2, SAE1, Ku, PM-Scl100, PMScl75, Jo-1, SRP, PL-7, PL-12, EJ, and OJ. Anti-HMGCR antibodies were searched using a commercial ELISA kit (Inova Diagnostics, Inc., San Diego, CA).

Instrumental examinations included EMG and nerve conduction studies (NCSs). Systemic involvement was evaluated as follows: cardiologic evaluation with echocardiography and ECG, pneumologic evaluation with spirometry and nocturnal oximetry, and swallowing assessment through oro-pharyngoesophageal scintigraphy (OPES).

\section{Muscle Biopsy}

All patients underwent muscle biopsy for diagnostic purposes at the time of their first evaluation in our center. Muscle biopsies were processed according to standard procedures, and routine histologic stains were analyzed. ${ }^{14}$ Immunofluorescence was performed on 6 - $\mu \mathrm{m}$-thick sections using FITC-conjugated phalloidin (Sigma, St. Louis, MO) and the following primary antibodies: monoclonal anti-human CD4, CD8, CD20, CD68, and $\mathrm{C} 5 \mathrm{~b} 9$ antigens (Sigma, St. Louis, MO), and type I and II HLA (US Biological, Swampscott, MA), dystrophin (N-terminal and C-terminal from Novocastra/Leica Biosystems, Germany; rod domain from Merck-Millipore, MA), alpha-sarcoglycan and gamma-sarcoglycan (Novocastra/Leica Biosystems, Germany), alpha-dystroglycan (Merck-Millipore, MA), merosin (MerckMillipore, MA), and caveolin-3 (BD Biosciences, CA).

\section{MRI Evaluation}

Patients underwent upper and lower girdle muscle MRI according to published protocols ${ }^{15,16}$ before and after 
Table 1 Clinical and Instrumental Findings of Our Cohort

\begin{tabular}{|c|c|c|c|c|c|c|}
\hline Pt. ID & P1 & P2 & P3 & P4 & P5 & P6 \\
\hline Sex & $\mathrm{F}$ & $\mathrm{F}$ & $\mathrm{F}$ & $\mathrm{F}$ & $\mathrm{F}$ & $\mathrm{F}$ \\
\hline Age at onset, y & 58 & 59 & 62 & 37 & 62 & 40 \\
\hline $\begin{array}{l}\text { Diagnostic delay } \\
\text { (mo) }\end{array}$ & 9 & 20 & 24 & 24 & 12 & 12 \\
\hline $\begin{array}{l}\text { Symptom at } \\
\text { onset }\end{array}$ & $\begin{array}{l}\text { Proximal UULL } \\
\text { weakness }\end{array}$ & Dropped head & Proximal UULL weakness & $\begin{array}{l}\text { Dropped head and } \\
\text { proximal UULL } \\
\text { weakness }\end{array}$ & $\begin{array}{l}\text { Proximal UULL } \\
\text { weakness and } \\
\text { dysphagia }\end{array}$ & Dropped head \\
\hline Dropped head & Yes & Yes & Yes & Yes & Yes & Yes \\
\hline \multirow[t]{2}{*}{ Dysphagia $^{a}$} & Yes (+dysphonia) & Yes & Yes & No & Yes (+dysphonia) & No \\
\hline & & $\begin{array}{l}\text { Esophageal } \\
\text { alteration }\end{array}$ & $\begin{array}{l}\text { Pharyngeal and } \\
\text { esophageal alteration }\end{array}$ & & $\begin{array}{l}\text { Pharyngeal and } \\
\text { esophageal } \\
\text { alteration }\end{array}$ & \\
\hline $\begin{array}{l}\text { Proximal upper } \\
\text { limb weakness }\end{array}$ & Yes & Yes & Yes & Yes & Yes & Yes \\
\hline $\begin{array}{l}\text { Lower limb } \\
\text { weakness }\end{array}$ & No & Yes & Yes & No & No & No \\
\hline Facial weakness & $\begin{array}{l}\text { Yes (upper and } \\
\text { lower part) }\end{array}$ & $\begin{array}{l}\text { Yes (upper and } \\
\text { lower part) }\end{array}$ & Yes (upper and lower part) & Yes (lower part) & Yes (lower part) & Yes (lower part) \\
\hline Scapular winging & Present & Present & Absent & Present & Absent & Absent \\
\hline $\begin{array}{l}\text { Respiratory } \\
\text { involvement }\end{array}$ & $\begin{array}{l}\text { Moderate } \\
\text { obstructive lung } \\
\text { disease } \\
\text { FVC }=50 \%\end{array}$ & $\begin{array}{l}\text { None } \\
\text { FVC }=108 \%\end{array}$ & $\begin{array}{l}\text { Moderate obstructive } \\
\text { and restrictive lung disease, } \\
\text { FVC }=66 \% \text {, moderate } \\
\text { MEP }>\text { MIP reduction }\end{array}$ & None & $\begin{array}{l}\text { Mild MEP }>\text { MIP } \\
\text { reduction }\end{array}$ & $\begin{array}{l}\text { Mild restrictive } \\
\text { lung disease }\end{array}$ \\
\hline $\begin{array}{l}\text { Maximum } \\
\text { CK level }\end{array}$ & $3 x$ & $5 \times$ & $3 x$ & $3 x$ & $4 \times$ & $2 x$ \\
\hline EMG & $\begin{array}{l}\text { Myopathic MUPs } \\
\text { and fibrillation } \\
\text { potentials }\end{array}$ & $\begin{array}{l}\text { Myopathic MUPs } \\
\text { and fibrillation } \\
\text { potentials }\end{array}$ & Myopathic MUPs & $\begin{array}{l}\text { Myopathic MUPs and } \\
\text { fibrillation potentials }\end{array}$ & Myopathic MUPs & $\begin{array}{l}\text { Myopathic MUPs } \\
\text { amd fibrillation } \\
\text { potentials }\end{array}$ \\
\hline ANA & $\begin{array}{l}\text { Positive 1:160; } \\
\text { nucleolar pattern }\end{array}$ & $\begin{array}{l}\text { Positive 1:160; } \\
\text { nucleolar pattern }\end{array}$ & $\begin{array}{l}\text { Positive 1:160; nucleolar } \\
\text { pattern }\end{array}$ & $\begin{array}{l}\text { Positive 1:1,280; } \\
\text { nucleolar pattern }\end{array}$ & $\begin{array}{l}\text { Positive 1:320; } \\
\text { nucleolar pattern }\end{array}$ & $\begin{array}{l}\text { Positive 1:80; } \\
\text { nucleolar pattern }\end{array}$ \\
\hline MSA/MAAs & Negative & Negative & Negative & Negative & Negative & SS-A, RNP \\
\hline $\begin{array}{l}\text { Anti-AChR } \\
\text { antibodies }\end{array}$ & Negative & Positive & Positive & NA & Positive & Negative \\
\hline $\begin{array}{l}\text { Past medical } \\
\text { history }\end{array}$ & MGUS; glaucoma & $\begin{array}{l}\text { Hypertension } \\
\text { OSAS }\end{array}$ & COPD & $\begin{array}{l}\text { Raynaud } \\
\text { phenomenon and } \\
\text { Hashimoto thyroiditis }\end{array}$ & None & $\begin{array}{l}\text { Raynaud } \\
\text { phenomenon and } \\
\text { scleroderma }\end{array}$ \\
\hline
\end{tabular}

Abbreviations: $A C h R=$ acetylcholine receptor; $A N A=$ antinuclear antibody $; C K=$ creatine kinase; $C O P D=$ chronic obstructive pulmonary disease; $F V C=$ forced vital capacity; MUP = motor unit potential; MAA myositis-associated antibody; MGUS = monoclonal gammopathy of uncertain significance; MSA = myositisspecific antibody; NA = not assessed; OSAS = obstructive sleep apnea syndrome; UULL = upper limbs.

a Data from OPES.

immunosuppressive treatment. Pretreatment upper girdle MRI was not available for patient 6. T1-weighted (T1w) images were examined to detect fatty infiltration of specific muscles, and short-tau inversion recovery (STIR) sequences were evaluated for the presence or absence of muscle edema.

\section{Data Availability}

Anonymized data will be shared by reasonable request from any qualified investigator who wants to analyze questions that are related to the published article.

\section{Results}

\section{Patients and Clinical Findings}

Six patients of a total of $178 \mathrm{IIMs}$ were identified; all were females. One of these patients had been previously described. ${ }^{8}$ Mean age at onset was 53.0 \pm 11.4 years (range 37-62 years), and mean disease duration at diagnosis and treatment start was $16.8 \pm 6.5$ months (range 9-24 months). Two patients had Raynaud phenomenon and previous history of autoimmune disease (scleroderma and Hashimoto thyroiditis, respectively). Five patients were referred with the clinical suspicion of FSHD, 
not confirmed by molecular testing, and one as PM, previously treated with low dose of oral prednisone. Most common symptoms at onset were head drop and difficulty in raising arms. One patient complained of swallowing difficulties since onset, later developed by other 3 subjects.

On neurologic examination, neck muscle weakness was present in all patients, with neck extensors more involved than flexors in 5 of 6 patients (MRC grade 1-4), together with proximal upper limb involvement (MRC 3-4), milder distal weakness, especially in the wrist and finger extensors, and facial weakness. Proximal lower limb weakness was clinically evident in 2 cases (MRC 3-4). Scapular winging was detected in 3/6 patients. Clinical details of all the subjects are summarized in table 1 .

\section{Laboratory and Instrumental Findings}

All the patients showed mildly elevated CK levels $(2-5 \times$ normal values) and resulted positive for ANA test with a nucleolar pattern. Anti-AChR antibodies were tested in 5 patients and found positive in 3 of them, whereas MSA panel was unremarkable. All patients underwent molecular testing for FSHD1 and resulted negative for the presence of a D4Z4 macrosatellite repeat contraction in the subtelomeric region of chromosome $4 q 35$. Neurophysiologic studies revealed a myopathic recruitment pattern with fibrillation potentials at rest on needle EMG in all patients and normal NCS. Repetitive nerve stimulation (accessory and/or axillary nerve) on proximal muscles that were clinically weak was normal in all patients. Spirometry and nocturnal oximetry evaluation revealed respiratory involvement in 3 patients: patient 3 had a moderate mixed obstructive and restrictive lung disease and a marked reduction of maximal inspiratory pressures, never requiring assisted ventilation; patient 5 had asymptomatic mild restrictive lung disease with moderate reduction of maximal expiratory pressure; patient 2 was diagnosed with obstructive sleep apnea syndrome. Cardiac evaluation was performed in all patients, including both cardiac ultrasound and 24-hour EKG, and was normal in all of them with the exception of frequent ventricular extrasystoles in patient 2 . OPES was abnormal in 4 patients, showing an alteration in both pharyngeal and esophageal muscle motility.

All patients underwent chest and abdomen CT, and interstitial lung disease or concurrent malignancies were excluded at the time of first neurologic assessment.

\section{Muscle Pathology}

Biopsies were taken from deltoid muscles (3 patients), vastus lateralis, and biceps brachii. In patient 2, semimembranosus muscle was chosen for its STIR-hyperintense signal on muscle MRI. Muscle pathology features are summarized in table 2. All samples showed myopathic abnormalities, i.e., increased muscle fiber size variability and internalization of myonuclei. Mild to moderate increase of endomysial connective tissue was present in 4 specimens. All these changes were prominent in patient 3, with a dystrophic-like appearance. A moderate amount of muscle fiber necrosis was present in 2 specimens, whereas scattered necrotic fibers were found in all of them. Only 1 specimen presented perifascicular atrophy. Immunofluorescence for sarcolemmal proteins was normal in all samples.

All biopsies showed various degrees of inflammatory changes (figure 1, A-C). HLA class I was abnormally expressed on the sarcolemma of most or all the muscle fibers in all samples. Inflammatory infiltrates or, more often, focal accumulations of mononuclear cells were found in the endomysium and, less frequently, in the perimysium in all samples. Perivascular inflammation was found in all specimens, particularly relevant in 4 of them. The foci of mononuclear inflammatory cells mainly consisted of $\mathrm{CD} 20^{+}$lymphocytes and, to a lesser extent, of $\mathrm{CD} 4^{+}$ cells (figure 1, D-F). CD68 ${ }^{+}$macrophages were present both in necrotic fibers and in perivascular infiltrates. Mild deposition of membrane attack complex (MAC) in the endomysial connective tissue was found in 2 specimens. Three samples presented reduced number of muscle capillaries, with enlargement in 2 of them. MAC deposition on muscle capillaries was present only in patient 6.

\section{Treatment and Follow-up}

All patients were treated with oral prednisone $(1 \mathrm{mg} / \mathrm{kg} / \mathrm{d})$ as first-line therapy. In 5 patients, a steroid-sparing immunosuppressant was added: azathioprine in 4 patients and methotrexate in the patient with concomitant scleroderma. Repeated courses of monthly IV immunoglobulins (IVIgs) at the dose of $2 \mathrm{~g} / \mathrm{kg}$ were also administered to 4 patients in the first year of treatment.

Follow-up of patients ranged from 23 to 159 months, and the main findings are summarized in table 3 . Clinical improvement was obtained in 5/6 patients with complete proximal upper limb function recovery in 3 cases and amelioration of shoulder abduction in all cases; on the contrary, neck weakness was found particularly resistant to therapy, with full recovery of strength of neck extensors in patients 1 and 4 and of neck flexors only in 1 patient. Three of 4 patients, who complained of swallowing difficulties at baseline, reported subjective improvement after treatment, although OPES was not significantly modified. Patient 3 , despite amelioration of upper limb and neck weakness, experienced aspiration pneumonia and died of sepsis 18 months after treatment initiation and 47 months after onset of symptoms. Patient 6, after an initial response to treatment, predominantly in proximal upper limb strength, showed insufficient adherence to treatment and stopped neurologic follow-up and all medications after 6 months. She was diagnosed with a medullary carcinoma of the breast 3 years after onset of symptoms and treated with a combination of surgery and adjuvant therapy. Muscle weakness progressed over time, with severe worsening of neck extensor and upper limb proximal weakness and involvement of axial and proximal lower limbs. Four years later, she was put on subcutaneous immunoglobulins, with subjectively reported mild improvement. At the time of the last evaluation, 13 years after onset, she could walk only for short distances showing a 
Table 2 Muscle Pathology

\begin{tabular}{|c|c|c|c|c|c|c|}
\hline Pt. ID & P1 & P2 & P3 & P4 & P5 & P6 \\
\hline Muscle & Deltoid & Semimembranosus & Vastus lateralis & Deltoid & Deltoid & Biceps brachii \\
\hline Fiber size variability & + & ++ & +++ & + & + & ++ \\
\hline Increased endomysial connective tissue & 0 & + & ++ & + & 0 & ++ \\
\hline \multicolumn{7}{|l|}{ Inflammatory infiltrates } \\
\hline Perimysial & ++ & + & + & 0 & 0 & + \\
\hline Endomysial & + & ++ & + & + & + & ++ \\
\hline Perivascular & ++ & + & ++ & ++ & + & ++ \\
\hline Muscle fiber necrosis & 0 & ++ & + & + & + & ++ \\
\hline Perifascicular atrophy & 0 & 0 & 0 & 0 & 0 & + \\
\hline \multicolumn{7}{|l|}{ Capillary abnormalities } \\
\hline Reduced & + & 0 & ++ & 0 & 0 & ++ \\
\hline Enlarged & 0 & 0 & + & 0 & 0 & + \\
\hline CD4 & ++ & ++ & ++ & + & ++ & + \\
\hline CD8 & ++ & 0 & + & + & 0 & ++ \\
\hline CD20 & ++ & + & ++ & + & ++ & +++ \\
\hline CD68 & ++ & + & ++ & + & + & ++ \\
\hline C5b9 & 0 & 0 & + & 0 & 0 & + \\
\hline
\end{tabular}

Abbreviations: $\mathrm{MHC}=$ major histocompatibility complex.

Semiquantitative scale ranging from 0 (absent) to +++ (abundant).

waddling gait, head drop, and anterior flexion of the trunk and had severe limitation in arm abduction $\left(30^{\circ}\right)$, along with pectoral atrophy, dysphagia, and nasal speech.

Given the presence of anti-AChR antibodies, 2 patients (patients 3 and 5) started treatment with oral pyridostigmine (up to $60 \mathrm{mg} 3$ times a day). Both patients suspended this treatment after 1 month due to the lack of any clinical improvement.

\section{Muscle MRI}

MRI scans of upper girdle and lower limbs were available for 5 patients before and after treatment. Patient 6 underwent only lower limb MRI pretreatment, that did not show abnormalities both on T1w- and STIR sequences, and a second scan, also including the upper girdle, was repeated after 13 years. All patients showed an exclusive or disproportionate involvement in the upper girdle and neck muscles compared with lower limbs (figure 2). Neck muscles were the most consistently involved: mild to moderate fatty changes were found in neck extensors in all patients, and STIR hyperintensity (STIR+) of these muscles was also noted in 2 patients. Sternocleidomastoid and trapezius muscles were symmetrically hypotrophic in all patients, especially in patient 3. Other muscles, such as pectoralis major, rhomboids, serratus anterior, and levator scapulae, were only sporadically and mildly involved. Trapezius muscles were STIR+ in all patients, whereas both trapezius and rhomboids were STIR+ in 4 patients (figure 3 ).

Lower limb muscles were spared in all patients with exception of patient 3 , who showed mild to moderate fatty infiltration of

Figure 1 Pathology Findings in Brachio-Cervical Inflammatory Myopathy
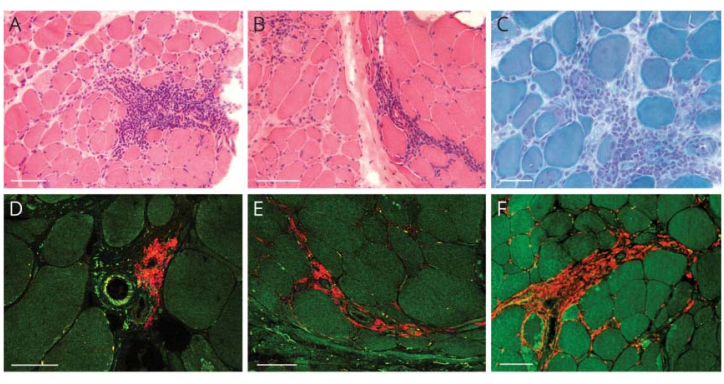

Hematoxylin and eosin (A and B) and modified Gomori trichrome (C) staining showing mononuclear cell inflammatory infiltrates with a primarily perivascular distribution, spreading into the endomysium, increased muscle fiber size variability with few necrotic fibers (asterisk), and mild endomysial fibrosis. Immunofluorescence images showing $\mathrm{CD} 2 \mathrm{O}^{+} \mathrm{B}$ cells (red, D and $E$ ) and $C D 4^{+} T$ cells $(r e d, F)$ in the inflammatory infiltrates. Sarcoplasma is counterstained in green with FITC-conjugated phalloidin (D, E, and F). Magnification bar stands for $50 \mu \mathrm{m}$ in (A and B) and for $100 \mu \mathrm{m}$ in (C-F). 
Table 3 Pre- and Post-treatment Clinical Assessments

\begin{tabular}{|c|c|c|c|c|c|c|}
\hline Pt. ID & P1 & P2 & P3 & P4 & P5 & P6 \\
\hline Follow-up (mo) & 35 & 88 & 23 & 55 & 53 & $159^{a}$ \\
\hline \multicolumn{7}{|l|}{ Neck weakness } \\
\hline Neck extensors & $+/ 0$ & $+++/+$ & $+++/++$ & $++/ 0$ & $+++/+$ & $+++/++/+++$ \\
\hline Neck flexors & $+++/ 0$ & $++/++$ & $+++/++$ & $+/+$ & $+++/++$ & $+++/++/+++$ \\
\hline \multicolumn{7}{|l|}{$\begin{array}{l}\text { Upper limb weakness: } \\
\text { baseline/last follow-up }\end{array}$} \\
\hline Proximal & $++/+$ & $++/+$ & $++/+$ & $+/ 0$ & $++/ 0$ & $+/ 0 /++$ \\
\hline Distal & $+/+$ & $+/ 0$ & $+/ 0$ & $+/+$ & $++/+$ & $++/+/++$ \\
\hline $\begin{array}{l}\text { Lower limb weakness: } \\
\text { baseline/last follow-up }\end{array}$ & $0 / 0$ & $+/ 0$ & $++/++$ & $0 / 0$ & $0 / 0$ & $0 / 0 /+$ \\
\hline Arm abduction & $\begin{array}{l}45^{\circ} \mathrm{R}, 30^{\circ} \mathrm{L} / 65^{\circ} \mathrm{R} \\
85^{\circ} \mathrm{L}\end{array}$ & $75^{\circ} / 90^{\circ}$ & $70^{\circ} / 80^{\circ}$ & $80^{\circ} / 90^{\circ}$ & $45^{\circ} / 90^{\circ}$ & $45^{\circ} / 80^{\circ} / 30^{\circ}$ \\
\hline Treatment & $\begin{array}{l}\text { Prednisone, IVIg, } \\
\text { azathioprine }\end{array}$ & $\begin{array}{l}\text { Prednisone, } \\
\text { IVlg }\end{array}$ & $\begin{array}{l}\text { Prednisone, IVIg, } \\
\text { azathioprine }\end{array}$ & $\begin{array}{l}\text { Prednisone, } \\
\text { azathioprine }\end{array}$ & $\begin{array}{l}\text { Prednisone, } \\
\text { azathioprine }\end{array}$ & $\begin{array}{l}\text { Prednisone, IVIg, } \\
\text { methotrexate, SCIg }\end{array}$ \\
\hline
\end{tabular}

Abbreviations: IVIg = IV immunoglobulin; L = left; NA = not available; R = right; SCIg = subcutaneous immunoglobulin.

Summary of clinical evaluations at baseline (pretreatment) and at last follow-up after treatment. Muscle strength was assessed with manual muscle testing (MRC scores 0-5), and muscle weakness was classified as $0(\mathrm{MRC}=5),+(\mathrm{MRC}=4),++(\mathrm{MRC}=3)$, and $+++(\mathrm{MRC}=0-2)$. Baseline evaluation was performed during the first visit at our center.

${ }^{a}$ For patient 6, we reported 3 different time points: first clinical evaluation/posttreatment 6-month follow-up/last available follow-up, 13 years after diagnosis.

iliopsoas and posterior leg muscles, as well as STIR hyperintensities in the adductor magnus, distal portion of the vasti and posterior leg muscles (figure $4 \mathrm{~A}$ ).

A second MRI was repeated after a mean of 14.6 months (range 6-22 months) from treatment initiation. At follow-up, the number of STIR+ muscles was considerably lower in all patients with a mean change from 12.4 (range: 7-16) STIR+ muscles pretreatment to 2.2 (range: $0-9$ ) posttreatment. No STIR+ muscles were detected in 2 patients, and other 2 patients had only 1 STIR+ muscle at follow-up. In patient 3, despite a reduction of the number of STIR+ muscles (from 15 to 9), hyperintensities lasted up to 16 months since treatment initiation, especially in the trapezius, rhomboids, and lower limb muscles. In patient 6, the follow-up MRI scan showed severe fatty replacement of neck and upper girdle muscles along with paraspinal and abdominal muscles, still with relative sparing of the lower limbs (figure 4B).

\section{Discussion}

In this study, we described baseline and posttreatment clinical and radiologic findings in a cohort of 6 female patients diagnosed with BCIM, with a long follow-up, up to 13 years.

All presented head drop, difficulty in raising arms, and facial weakness, which is an uncommon onset among IIMs. Weakness of distal upper limb muscles, especially in the posterior forearm, was also always present in our cohort although not frequently reported in BCIM so far. ${ }^{10}$ Lower limb involvement was rare, even if it might be present in very advanced disease.

The clinical spectrum of BCIM may thus vary from a myopathy confined to the neck and proximal upper limb muscles to, more rarely and especially if untreated, a severe disorder encompassing also axial and lower limb muscle involvement, dysphagia, and respiratory impairment. Here, we presented 2 examples of the disabling end of this spectrum: patient 3 , with unsatisfying treatment response and poor outcome, and patient 6 who, due to insufficient therapy, may represent an example of the natural history of the disease.

A peculiar clinical feature is the presence of facial weakness. ${ }^{7,8}$ This finding, in addition to the difficulties in arm abduction and scapular winging, raised the initial clinical suspicion of FSHD for most of our patients. The slowly progressive course and this misleading clinical picture led to a mean diagnostic delay of approximately 1.5 years, which was comparable to previous studies, yet undesirable in a potentially treatable condition. ${ }^{10,11}$ Muscle MRI examination could narrow this delay and is instrumental in differentiating this entity from other IIMs, motor neuron diseases, or hereditary myopathies. Severe fatty replacement of neck extensors and sternocleidomastoid atrophy, along with diffuse STIR hyperintensities in upper girdle muscles and relative preservation of lower limbs, are the most striking features in BCIM.

In the other IIMs, scapular girdle and upper limbs are not routinely scanned, as the most common radiologic alterations are in the pelvic girdle and lower limbs. ${ }^{17} \mathrm{Few}$ articles 
Figure 2 Disproportionate Involvement of Upper Limb Muscles in Brachio-Cervical Inflammatory Myopathy

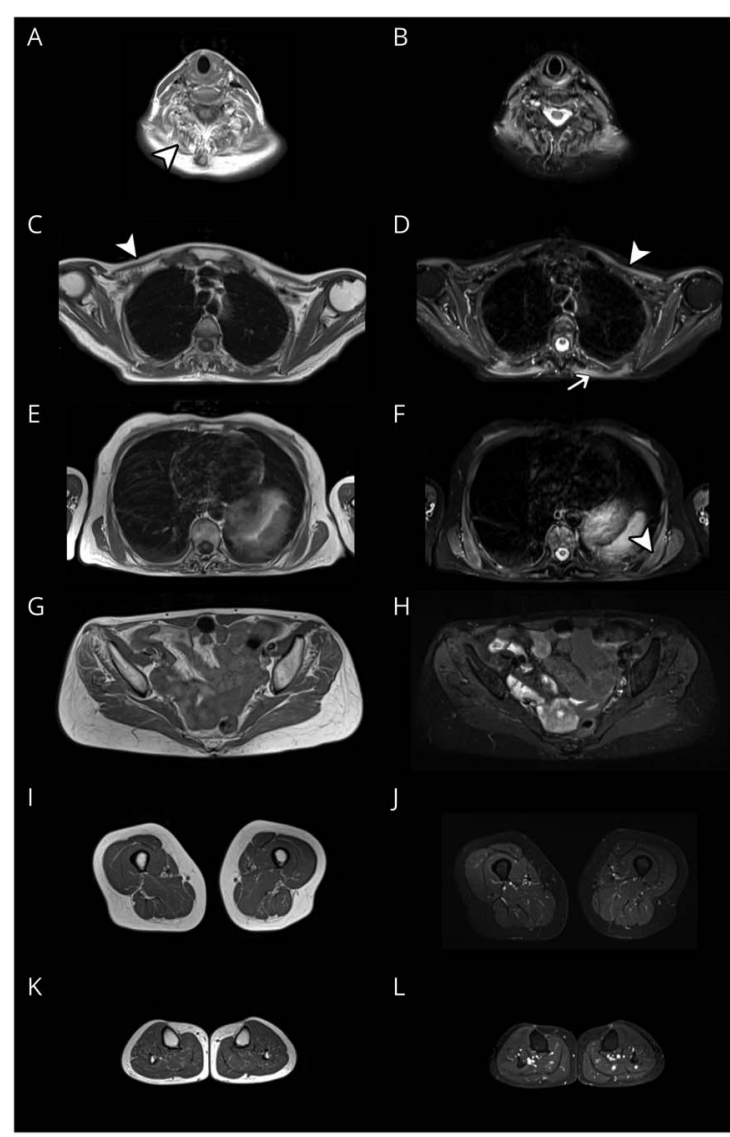

Pretreatment muscle MRI findings from patient 5, showing disproportionate involvement of upper (A-F) compared with lower limb muscles (G-L). T1weighted images (A, C, E, G, I, and $K$ ) display fatty replacement of neck extensors and cervical paraspinal muscles (arrowhead, A) and diffuse atrophy of upper girdle muscles, especially pectoralis major (arrowhead, C). STIR sequences $(B, D, F, H, J$, and $L$ ) show diffuse hyperintense signal in most of the upper girdle muscles, such as pectoralis major (arrowhead, D), trapezius (arrow, D), and serratus anterior (arrowhead, F). Pelvis and lower limb muscles are spared in both T1 and STIR sequences.

reported inconsistent findings of STIR hyperintensities in trapezius and neck flexors muscles in IIMs, whereas others even discourage shoulder girdle and trunk muscles MRI scans in the diagnostic workup of IIMs. ${ }^{17,18}$ On the other hand, in motor neuron disorder, the most involved muscle is the supraspinatus. ${ }^{19}$ The frequent involvement of trapezius muscles and the presence of STIR positive muscles are shared by both BCIM and FSHD. Nevertheless, the severe involvement of neck muscles is unusual in FSHD, where neck extensors rarely show fatty replacement and sternocleidomastoid atrophy is usually asymmetric. ${ }^{16}$ Another possible differential diagnosis is sporadic late-onset nemaline myopathy, which may share with BCIM proximal upper limb weakness, together with neck extensor and facial involvement, but that can be differentiated by the presence of nemaline rods on muscle biopsy. ${ }^{20}$

From a histopathologic perspective, BCIM presents as a typical inflammatory myopathy, with HLA Class I upregulation on the sarcolemma, and small inflammatory perivascular and endomysial infiltrates mainly represented by $\mathrm{CD}_{2}{ }^{+}$ $\mathrm{B}$ cells and $\mathrm{CD} 4^{+} \mathrm{T}$ cells. Although first described as having a predominant perimysial pathology and peculiar endomysial C5b9 deposition, ${ }^{7}$ these findings were not consistently present in our cohort. This heterogeneity may suggest a wider histopathologic spectrum than previously reported.

Although we cannot exclude the presence of uncharacterized, disease-specific autoantibodies, we were not able to detect the presence of any of the known MSA/MAAs in our cohort of patients. In addition, we confirm that ANAs were present in all patients, and 3 also presented anti-AChR antibodies. Taken together, all these findings, along with the detection of B-cell components of inflammation and the association with other autoimmune disorders, support a role of the humoral immune system in the pathogenesis of BCIM.

Myasthenia gravis and IIM can also overlap in some patients. In these peculiar situations, thymus pathology is very frequent, repetitive nerve stimulation is abnormal, and muscle MRI demonstrates a predominant involvement of lower limb muscles. $^{21}$ In our cohort, repetitive nerve stimulation was performed on proximal, weak muscles and resulted normal in all patients. No patient reported fluctuation of symptoms, and evidence of

Figure 3 Representative Muscle MRI Findings in Brachio-Cervical Inflammatory Myopathy

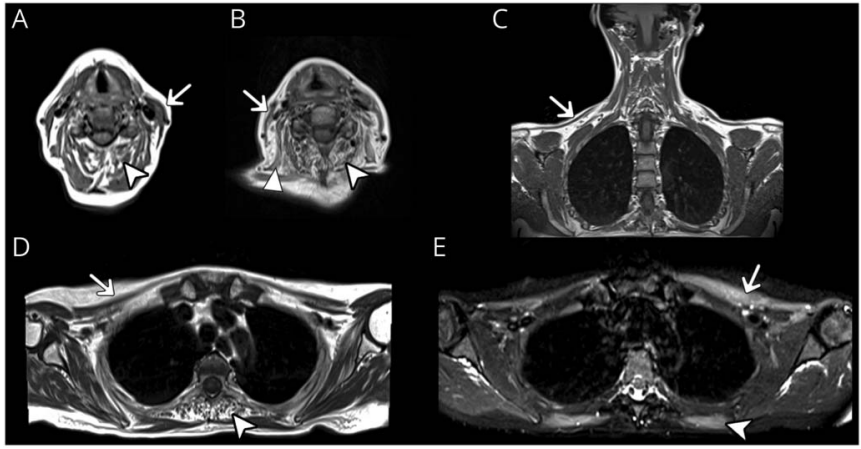

T1-weighted scans show the involvement of neck muscles in patients 1 (A) and $3(B)$, with fatty replacement of neck extensors (arrowhead, A and B) and levator scapulae (triangle, B), and hypotrophy of the sternocleidomastoid (arrows, A and B), particularly severe in patient 3. T1-weighted images of the scapular girdle in 2 different patients (C, coronal slice, and D, axial slice), respectively, show selective atrophy of trapezius in patient 4 (arrow, C) and diffuse and severe muscle atrophy in patient 3, more pronounced for the thoracic paraspinal (arrowhead, D) and pectoralis major muscles (arrow, D). STIR sequences in patient 4 (E) display hyperintensities in several muscles, such as pectoralis major (arrow) and rhomboids (arrowhead). 


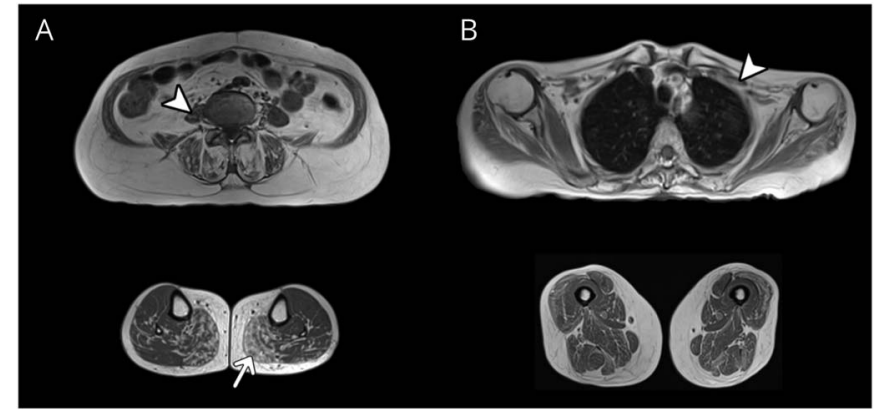

Pretreatment T1-weighted lower limb scans of patient 3 (A) displayed hypotrophy of iliopsoas (arrowhead) and moderate/severe bilateral fatty changes of posterior lower leg muscles (arrow). In patient 6 (B), long-term follow-up MRI images revealed extensive atrophy of pectoralis major (arrowhead) and other scapular girdle muscles with mild diffuse hypotrophy and fatty infiltration of the thigh muscles. muscle fatigability was not found. Moreover, 2 anti-AChRpositive patients started oral pyridostigmine without any clinical improvement, and thymic disease was excluded in all patients.

The association between IIMs (especially DM) and malignancy is well known and has been extensively reported in retrospective cohort studies and metanalyses. ${ }^{22-24}$ In our cohort, 1 patient was diagnosed with breast medullary carcinoma within 3 years from myositis onset. The close temporal relationship between the 2 conditions may support the hypothesis of a paraneoplastic phenomenon, although the differential course of the 2 diseases is in contrast with this hypothesis, as the patient was declared on remission for the malignancy while the myositis progressed. Moreover, breast medullary cancer is rarely associated with paraneoplastic syndromes, and the patient also had scleroderma, which itself has been associated with cancer. ${ }^{25,26}$ In any case, this association highlights the importance of tumor screening for patients with BCIM.

Despite a consensus on therapy for IIMs is still lacking, steroids are commonly used as the first-line agent and are often associated with steroid-sparing immunosuppressants. A number of other additional therapies have been tried, including IVIg and plasma exchange or a combination of both, and the outcome was generally good in previously published BCIM cases. ${ }^{7,9-11}$ However, the heterogeneous treatment strategies make it difficult to select the best approach for a given patient, and the treatment choice is commonly guided by patients' comorbidities, side effects, and, finally, physicians' experience. In our population, this approach led to clinical and radiologic improvement in all but 1 patient. However, neck muscle weakness, especially of neck flexors, was relatively resistant to therapy. At the time of diagnostic evaluation, neck muscles showed severe fatty replacement and atrophy on MRI. This finding could be expression of a chronic irreversible process explaining the lack of treatment response of this muscle group.

\section{Conclusion}

BCIM presents typical clinical and radiologic features and is not associated with known MSA antibodies, whereas the degree of severity may be broader than previously described. Muscle MRI can be helpful in distinguishing this disease from other acquired and hereditary myopathies and is instrumental in addressing the correct diagnosis of BCIM, which is crucial for timely treatment administration, possibly before fatty infiltration and atrophy occur.

Although the exiguous number of patients represents a limitation of the study and prevents significant correlations, factors that influence the outcome may include the extent of changes on MRI, the delay in starting the appropriate treatment, and the severity of dysphagia. Indeed, early diagnosis and treatment initiation are fundamental to prevent muscle fatty replacement or atrophy and irreversible weakness. When treatment is inadequate or lacking, the disease invariably progresses toward a severe phenotype, leaving very little space to further intervention.

Finally, despite definite answers will require a more extensive cohort of patients, cancer screening could be advisable in every patient diagnosed with BCIM, as in the other IIMs.

\section{Study Funding}

No targeted funding reported.

\section{Disclosure}

All authors have nothing to declare regarding the content of this manuscript. Go to Neurology.org/NN for full disclosures.

\section{Publication History}

Received by Neurology: Neuroimmunology \& Neuroinflammation December 2, 2020. Accepted in final form March 17, 2021.

\section{Appendix Authors}

\begin{tabular}{|c|c|c|}
\hline Name & Location & Contribution \\
\hline $\begin{array}{l}\text { Matteo } \\
\text { Lucchini, MD }\end{array}$ & $\begin{array}{l}\text { UOC di Neurologia, } \\
\text { Fondazione Policlinico } \\
\text { Universitario "A. Gemelli" } \\
\text { IRCCS; Università Cattolica } \\
\text { del Sacro Cuore, Rome, Italy }\end{array}$ & $\begin{array}{l}\text { Designed and } \\
\text { conceptualized the study; } \\
\text { analyzed the data; and } \\
\text { drafted the manuscript for } \\
\text { intellectual content }\end{array}$ \\
\hline
\end{tabular}


Appendix (continued)

\begin{tabular}{|c|c|c|}
\hline Name & Location & Contribution \\
\hline $\begin{array}{l}\text { Sara } \\
\text { Bortolani, MD }\end{array}$ & $\begin{array}{l}\text { UOC di Neurologia, } \\
\text { Fondazione Policlinico } \\
\text { Universitario "A. Gemelli" } \\
\text { IRCCS, Rome, Italy }\end{array}$ & $\begin{array}{l}\text { Major role in the acquisition } \\
\text { of data; analyzed the data; } \\
\text { and drafted the manuscript } \\
\text { for intellectual content. }\end{array}$ \\
\hline $\begin{array}{l}\text { Mauro } \\
\text { Monforte, } \\
\text { MD, PhD }\end{array}$ & $\begin{array}{l}\text { UOC di Neurologia, } \\
\text { Fondazione Policlinico } \\
\text { Universitario "A. Gemelli" } \\
\text { IRCCS, Rome, Italy }\end{array}$ & $\begin{array}{l}\text { Major role in the acquisition } \\
\text { of data and revised the } \\
\text { manuscript for intellectual } \\
\text { content }\end{array}$ \\
\hline $\begin{array}{l}\text { Manuela } \\
\text { Papacci, BSc }\end{array}$ & $\begin{array}{l}\text { Università Cattolica del } \\
\text { Sacro Cuore, Rome, Italy }\end{array}$ & Data analysis \\
\hline $\begin{array}{l}\text { Enzo Ricci, } \\
\text { MD, PhD }\end{array}$ & $\begin{array}{l}\text { UOC di Neurologia, } \\
\text { Fondazione Policlinico } \\
\text { Universitario "A. Gemelli" } \\
\text { IRCCS; Università Cattolica } \\
\text { del Sacro Cuore, Rome, Italy }\end{array}$ & $\begin{array}{l}\text { Revised the manuscript for } \\
\text { intellectual content }\end{array}$ \\
\hline $\begin{array}{l}\text { Massimiliano } \\
\text { Mirabella, } \\
\text { MD, PhD }\end{array}$ & $\begin{array}{l}\text { UOC di Neurologia, } \\
\text { Fondazione Policlinico } \\
\text { Universitario "A. Gemelli" } \\
\text { IRCCS; Università Cattolica } \\
\text { del Sacro Cuore, Rome, Italy }\end{array}$ & $\begin{array}{l}\text { Interpreted the data and } \\
\text { revised the manuscript for } \\
\text { intellectual content }\end{array}$ \\
\hline $\begin{array}{l}\text { Giorgio Tasca, } \\
\text { MD, PhD }\end{array}$ & $\begin{array}{l}\text { UOC di Neurologia, } \\
\text { Fondazione Policlinico } \\
\text { Universitario "A. Gemelli" } \\
\text { IRCCS, Rome, Italy }\end{array}$ & $\begin{array}{l}\text { Designed and } \\
\text { conceptualized the study; } \\
\text { interpreted the data; and } \\
\text { revised the manuscript for } \\
\text { intellectual content }\end{array}$ \\
\hline
\end{tabular}

\section{References}

1. Dalakas MC. Inflammatory muscle diseases. N Engl J Med. 2015;372:1734-1747.

2. Rider LG, Miller FW. Deciphering the clinical presentations, pathogenesis, and treatment of the idiopathic inflammatory myopathies. JAMA. 2011;305:183-190.

3. Mastaglia FL, Garlepp MJ, Phillips BA, Zilko PJ. Inflammatory myopathies: clinical, diagnostic and therapeutic aspects. Muscle Nerve. 2003;27:407-425.

4. Vattemi G, Mirabella M, Guglielmi V, et al. Muscle biopsy features of idiopathic inflammatory myopathies and differential diagnosis. Auto Immun Highlights. 2014;5: 77-85.

5. Bohan A, Peter JB. Polymyositis and dermatomyositis (first of two parts). N Engl J Med. 1975;292:344-347.

6. Mariampillai K, Granger B, Amelin D, et al. Development of a new classification system for idiopathic inflammatory myopathies based on clinical manifestations and myositis-specific autoantibodies. JAMA Neurol. 2018;75:1528-1537.
7. Pestronk A, Kos K, Lopate G, Al-Lozi MT. Brachio-cervical inflammatory myopathies: clinical, immune, and myopathologic features. Arthritis Rheum. 2006;54 1687-1696.

8. Tasca G, Mirabella M, Berrettini A, Monforte M, Tonali PA, Ricci E. Mixed connective tissue disease presenting as a peculiar myositis with poor muscle regeneration. Neurol Sci. 2011;32:171-174.

9. Gao AF, Saleh PA, Kassardjian CD, Vinik O, Munoz DG. Brachio-cervical inflammatory myopathy with associated scleroderma phenotype and lupus serology. Neurol Neuroimmunol Neuroinflamm. 2018;5:e410.

10. Khadilkar SV, Gupta N, Yadav RS. Cervicobrachial polymyositis. J Clin Neuromuscul Dis. 2014;16:59-68.

11. Suarez-Calvet X, Alonso-Perez J, Castellvi I, et al. Thrombospondin-1 mediates muscle damage in brachio-cervical inflammatory myopathy and systemic sclerosis. Neurol Neuroimmunol Neuroinflamm. 2020;7:e694.

12. Tasca G, Monforte M, De Fino C, Kley RA, Ricci E, Mirabella M. Magnetic resonance imaging pattern recognition in sporadic inclusion-body myositis. Muscle Nerve. 2015; 52:956-962

13. Maurer B, Walker UA. Role of MRI in diagnosis and management of idiopathic inflammatory myopathies. Curr Rheumatol Rep. 2015;17:67.

14. Tasca G, Ricci E, Penttilä S, et al. New phenotype and pathology features in MYH7related distal myopathy. Neuromuscul Disord. 2012;22:640-647.

15. Tasca G, Monforte M, Iannaccone E, et al. Muscle MRI in female carriers of dystrophinopathy. Eur J Neurol. 2012;19:1256-1260.

16. Tasca G, Monforte M, Iannaccone E, et al. Upper girdle imaging in facioscapulohumeral muscular dystrophy. PLoS One. 2014;9:e100292.

17. Filli L, Maurer B, Manoliu A, Andreisek G, Guggenberger R. Whole-body MRI in adult inflammatory myopathies: do we need imaging of the trunk? Eur Radiol. 2015; 25:3499-3507.

18. O'Connell MJ, Powell T, Brennan D, Lynch T, McCarthy CJ, Eustace SJ. Wholebody MR imaging in the diagnosis of polymyositis. AJR Am J Roentgenol. 2002; 179:967-971.

19. Gerevini S, Agosta F, Riva N, et al. MR imaging of brachial plexus and limb-girdle muscles in patients with amyotrophic lateral sclerosis. Radiology. 2016;279:553-561.

20. Monforte M, Primiano G, Silvestri G, et al. Sporadic late-onset nemaline myopathy: clinical, pathology and imaging findings in a single center cohort. J Neurol. 2018;265: 542-551.

21. Garibaldi M, Fionda L, Vanoli F, et al. Muscle involvement in myasthenia gravis: expanding the clinical spectrum of Myasthenia-Myositis association from a large cohort of patients. Autoimmun Rev. 2020;19:102498.

22. Yang Z, Lin F, Qin B, Liang Y, Zhong R. Polymyositis/dermatomyositis and malignancy risk: a metaanalysis study. J Rheumatol. 2015;42:282-291.

23. Yang $\mathrm{H}$, Peng $\mathrm{Q}$, Yin $\mathrm{L}$, et al. Identification of multiple cancer-associated myositisspecific autoantibodies in idiopathic inflammatory myopathies: a large longitudinal cohort study. Arthritis Res Ther. 2017;19:259.

24. Dobloug GC, Garen T, Brunborg C, Gran JT, Molberg Ø. Survival and cancer risk in an unselected and complete Norwegian idiopathic inflammatory myopathy cohort. Semin Arthritis Rheum. 2015;45:301-308.

25. Watad A, McGonagle D, Bragazzi NL, et al. Autoantibody status in systemic sclerosis patients defines both cancer risk and survival with ANA negativity in case with concomitant cancer having a worse survival. Oncoimmunology. 2019;8: e1588084.

26. Morrisroe $\mathrm{K}$, Hansen $\mathrm{D}$, Huq $\mathrm{M}$, et al. Incidence, risk factors, and outcomes of cancer in systemic sclerosis. Arthritis Care Res (Hoboken). 2020;72:1625-1635. 


\title{
Neurology \\ Neuroimmunology \& Neuroinflammation
}

\author{
Long-term Follow-up and Muscle Imaging Findings in Brachio-Cervical Inflammatory \\ Myopathy \\ Matteo Lucchini, Sara Bortolani, Mauro Monforte, et al. \\ Neurol Neuroimmunol Neuroinflamm 2021;8; \\ DOI 10.1212/NXI.0000000000001016
}

This information is current as of May 19, 2021

\begin{abstract}
Updated Information \& Services

References

Subspecialty Collections

Permissions \& Licensing

Reprints

including high resolution figures, can be found at:

http://nn.neurology.org/content/8/4/e1016.full.html

This article cites 26 articles, 2 of which you can access for free at: http://nn.neurology.org/content/8/4/e1016.full.html\#\#ref-list-1

This article, along with others on similar topics, appears in the following collection(s):

Autoimmune diseases

http://nn.neurology.org//cgi/collection/autoimmune_diseases

EMG

http://nn.neurology.org//cgi/collection/emg

MRI

http://nn.neurology.org//cgi/collection/mri

Muscle disease

http://nn.neurology.org//cgi/collection/muscle_disease its entirety can be found online at:

http://nn.neurology.org/misc/about.xhtml\#permissions

Information about ordering reprints can be found online:

http://nn.neurology.org/misc/addir.xhtml\#reprintsus
\end{abstract}

Information about reproducing this article in parts (figures,tables) or in

Neurol Neuroimmunol Neuroinflamm is an official journal of the American Academy of Neurology.

Published since April 2014, it is an open-access, online-only, continuous publication journal. Copyright

Copyright $\odot 2021$ The Author(s). Published by Wolters Kluwer Health, Inc. on behalf of the American

Academy of Neurology.. All rights reserved. Online ISSN: 2332-7812.

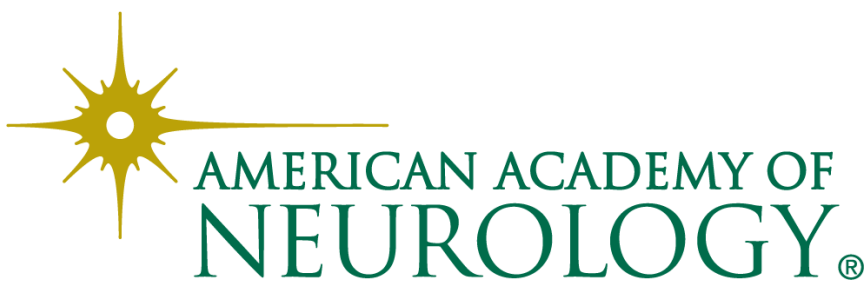

